\title{
Neumonía organizada criptogénica como presentación inicial de la artritis reumatoide
}

\author{
Cryptogenic organizing pneumonia as initial \\ presentation of rheumatoid arthritis
}

\author{
Juan Pablo Camargo, Lina María Villa, Plutarco García, \\ Edgar Sánchez, Alfredo SaAvedra • Bogotá D.C. (Colombia)
}

\begin{abstract}
Resumen
Se presenta el caso de una mujer de 65 años a quien se diagnostica neumonía organizada criptogénica (NOC), como primera manifestación de artritis reumatoide (AR). La paciente presentó tos y posteriormente disnea. La tomografía computarizada de tórax mostró opacidades parenquimatosas con broncograma de aire en los lóbulos superiores. Ocho semanas después presenta criterios clínicos y serológicos para AR, se diagnosticó NOC por biopsia abierta de pulmón, con excelente respuesta clínica y radiológica al tratamiento con corticosteroides. (Acta Med Colomb 2012; 37: 27-30)

Palabras clave: artritis reumatoide, neumonía organizada criptogénica, esteroide.
\end{abstract}

\begin{abstract}
The case of a 65 year old woman who was diagnosed with cryptogenic organizing pneumonia (NOC) as a first manifestation of rheumatoid arthritis (RA). The patient subsequently developed cough and dyspnea. Chest computed tomography showed parenchymal opacities with air bronchogram in the upper lobes. Eight weeks later, he presented clinical and serological criteria for RA, NOC diagnosis by open lung biopsy, with excellent clinical and radiological response to treatment with corticosteroids.
\end{abstract} (Acta Med Colomb 2012; 37: 27-30)

Keywords: rheumatoid arthritis, cryptogenic organizing pneumonia, steroid.
Dr. Juan Pablo Camargo Mendoza: Internista, Epidemiólogo Clínico, Fellow de Neumología, Universidad Nacional de Colombia; Dra. Lina María Villa Sánchez: Residente III de Medicina Interna Universidad Nacional de Colombia; Dr. Plutarco García Herreros: Unidad de Neumología Instituto Nacional de Cancerología, Universidad Nacional de Colombia; Dr. Edgar Sánchez Morales: Unidad de Neumología Instituto Nacional de Cancerología, Universidad Nacional de Colombia; Dr. Alfredo Saavedra Rodríguez: Unidad de Neumología Instituto Nacional de Cancerología, Universidad Nacional de Colombia. Bogotá D.C. (Colombia).

Correspondencia. Dr. Juan Pablo Camargo Mendoza. Bogotá D.C. (Colombia). E-mail: jpcamargome@unal.edu.co Recibido: 07/VI/2011 Aceptado: 26/I/2012

\section{Introducción}

La artritis reumatoide (AR) es una enfermedad inflamatoria sistémica asociada a un desorden autoinmune que afecta de manera preferencial el recubrimiento sinovial de las articulaciones. En países industrializados la AR afecta 0.5 a $1 \%$ de los adultos, con 5-50 casos nuevos por 100000 habitantes cada año. Es 2-3 veces más frecuente en mujeres. Típicamente la edad de diagnóstico se encuentra entre los 35-50 años. La sobrevida disminuye con respecto a la población general por las complicaciones extraarticulares y de forma exponencial después de los 65 años $(1,2)$.

Típicamente la AR inicia como una poliartritis simétrica afectando manos, muñecas, rodillas, tobillos y articulaciones del pie. La fatiga y la rigidez matinal prolongada son manifestaciones sistémicas comunes de la enfermedad. Las manifestaciones extraarticulares pueden ser de forma limitada o diseminada e incluyen nódulos reumatoides, serositis, vasculitis inflamatoria, enfermedad ocular, altera- ción hematológica, cardiaca y diversas formas de alteración pulmonar (1).

El compromiso pulmonar por AR es una fuente importante de morbilidad y mortalidad, las alteraciones más comunes son la enfermedad pulmonar intersticial (EPI), enfermedad de las vías respiratorias, nódulos reumatoides, y enfermedad pleural. Las manifestaciones respiratorias son más frecuentes a medida que avanza la enfermedad, pero pueden presentarse simultáneamente con los síntomas articulares o incluso precederlos. Muchas de ellas están directamente vinculadas al mecanismo fisiopatológico resultante o por la inflamación crónica subyacente. No obstante hay que destacar que las manifestaciones respiratorias se pueden asociar a la exposición y manejo con los fármacos antirrematoideos modificadores de la enfermedad (FARMEs) $(3,4)$. En esta oportunidad presentamos el caso de una mujer con AR y diagnóstico clínico, radiológico e histopatológico de neumonía organizada criptogénica (NOC) con adecuada respuesta a esteroide. 


\section{Presentación del caso}

Paciente femenina de 61 años, de raza mestiza con antecedente de hipotiroidismo posquirúrgico en tratamiento con levotiroxina, hipertensión arterial manejada con enalapril, cáncer de mama derecha canalicular infiltrante pobremente diferenciado grado nuclear, diagnosticado y manejado 14 años antes con cuadrantectomía, quimioterapia y radioterapia, con controles clínicos y radiográficos sin recaída. Como antecedente tóxico tabaquismo con un índice paquete/ año de 13.5. Consultó por síntomas de un mes de evolución consistentes en tos seca, posterior a esto expectoración de características mucoides, asociado a deterioro de la clase funcional y temperatura de $37.5^{\circ} \mathrm{C}$. Inicialmente manejada con antibiótico oral por siete días. Por persistencia de la disnea clase funcional II pero en ausencia de fiebre, o expectoración es valorada por neumología ambulatoriamente. Por antecedente oncológico solicita tomografía axial computarizada (TAC) de tórax, donde se evidenciaron opacidades parenquimatosas con broncograma aéreo en los lóbulos superiores (Figura 1). Espirometría con patrón obstructivo leve, sin respuesta al broncodilatador, con gases arteriales dentro de los límites normales.

A los dos meses la paciente presenta cuadro de poliartralgias simétricas, en interfalángicas proximales y metacarpofalángicas, rigidez matinal de dos horas de duración con mejoría parcial a los antiinflamatorios no esteroideos. Con mejoría de tos pero sin cambio en la disnea, el examen físico evidenciaba signos de sinovitis en manos y dificultad para la marcha en puntas por tarsalgia. Se solicita perfil inmunológico con ANAS (anticuerpos antinucleares) en 1:80 patrón moteado, factor rematoideo (FR) negativo, PCR (proteína C reactiva) $80 \mathrm{mg} / \mathrm{L}$, VSG (velocidad de sedimentación globular) de $40 \mathrm{~mm} / \mathrm{h}$. La paciente persistió con síntomas con aumento del dolor articular con extensión a rodillas de forma simétrica, se solicita anticuerpos anticitrulina IgG (Anti-CCP) positivos con valor de $188.96 \mathrm{U} / \mathrm{ml}$. En este contexto se considera posible compromiso pulmonar por AR y ante persistencia de la clínica y de alteraciones radiológicas se lleva a fibrobroncoscopia donde no se pudo realizar biopsia transbronquial por cifras tensionales elevadas, lavado broncoalveolar, reportó histiocitos 90\%, linfocitos 5\% y

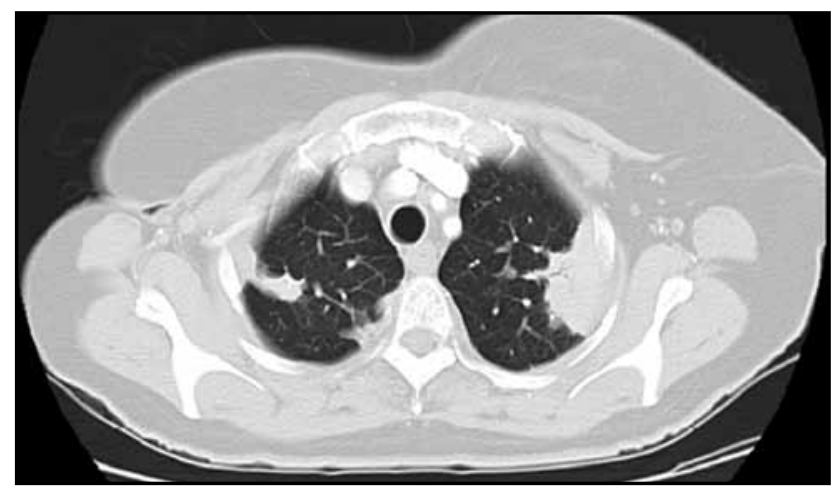

Figura 1. Opacidades parenquimatosas enlóbulos superiores. polimorfonucleres $5 \%$, con cultivos para gérmenes comunes y tuberculosis negativos. Por tal motivo se considera biopsia en cuña de la lesión del lóbulo superior izquierdo, cuya patología reportó tejido conectivo ocupando los bronquiolos terminales y el espacio alveolar, con aéreas de hemorragia e infiltrado mononuclear; hallazgos compatibles con NOC (Figuras 2 y 3). Se inició manejo con prednisona a $0.75 \mathrm{mg} /$ $\mathrm{kg}$ /día con mejoría clínica a las seis semanas, por lo cual se titula hasta dosis mínima de $5 \mathrm{mg}$ /día con control total de disnea y tos. TAC de tórax, control a las 12 semanas mostró resolución de las lesiones parenquimatosas (Figura 4), de igual forma el servicio de reumatología asoció FARMEs con adecuado control de dolor articular y disminución de PCR.

\section{Discusión}

La neumonía organizada criptogénica (NOC) fue considerada por muchos años como cambios en el pulmón asociados a infecciones; sin embargo, los estudios en las

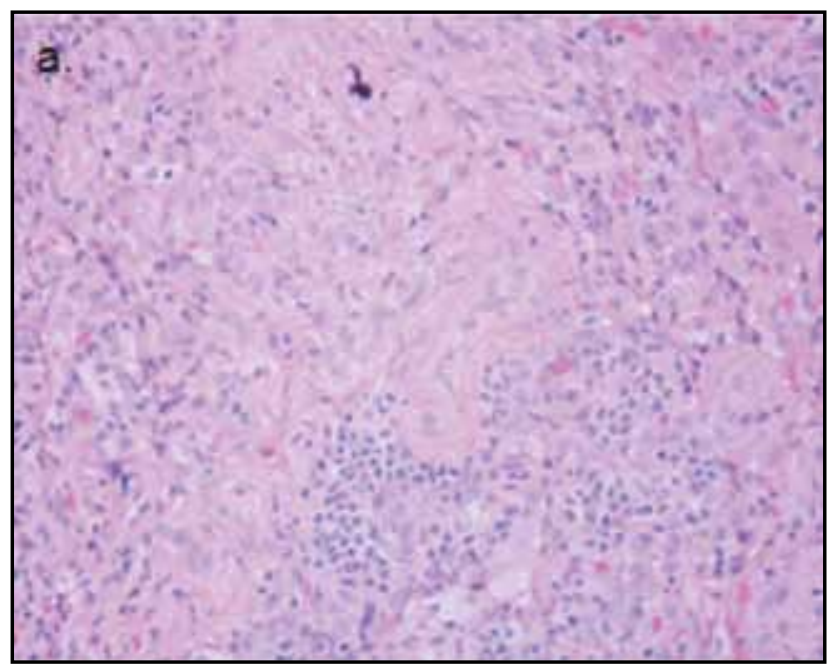

Figura 2. Biopsia en cuña pulmonar (HEx 100). Infiltrado inflamatorio mixto intraalveolar de predominio linfocítico.

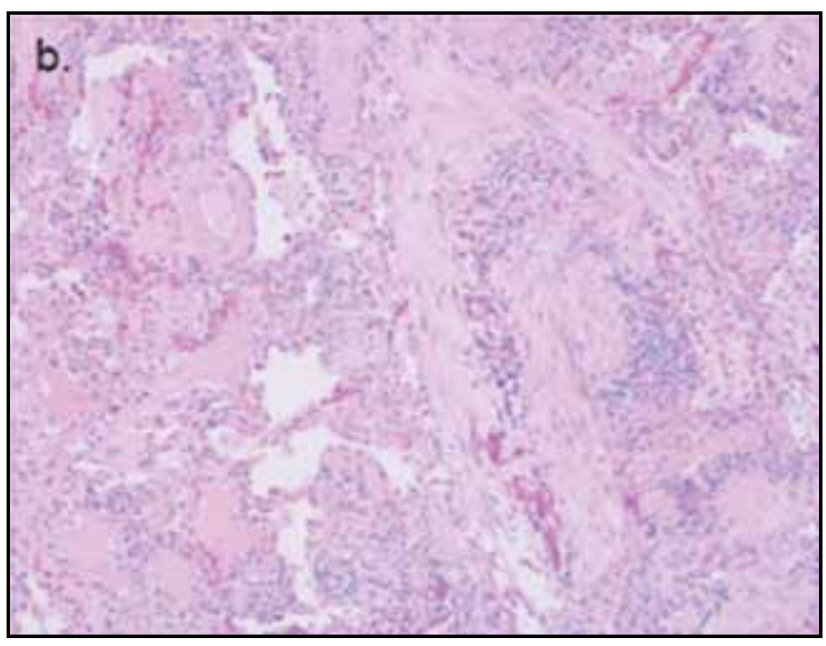

Figura 3. Biopsia en cuña pulmonar (HEx 100). Brotes de tejido de granulación consistente en miofibroblastos y fibroblastos incluidos en tejido conectivo. 


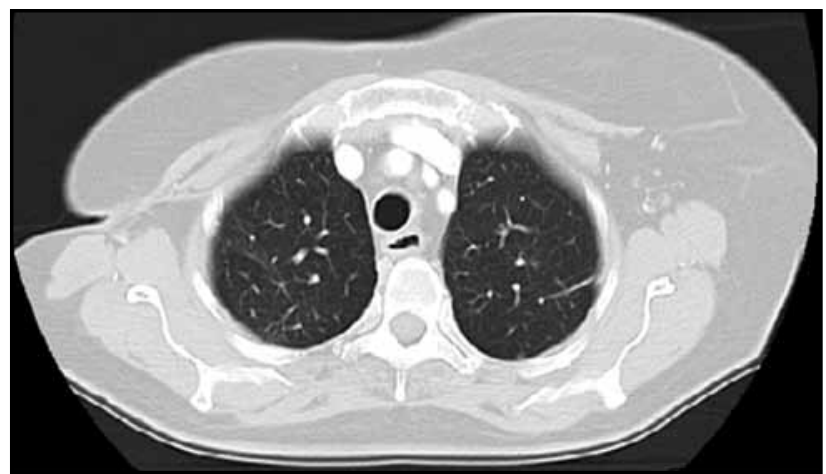

Figura 4. Control radiográfico a los tres meses del inicio de esteroide.

últimas décadas la han relacionado con múltiples patologías (5). Anteriormente conocida como BOOP (bronquiolitis obliterante con neumonía organizada), se caracteriza microscópicamente por complejos de fibroblastos, con tejido conectivo que protruye desde bronquiolos respiratorios y terminales, ocupando los ductus alveolares y alveolos. El tejido conectivo está formado por células inflamatorias, productos residuales, fibrina, formas celulares inmaduras y edema (6). Afecta por igual a mujeres y hombres con mayor frecuencia en el grupo etario entre los 50-60 años. Los no fumadores o exfumadores son afectados dos veces más que los fumadores activos, pero la proporción de no fumadores es mucho más alta en mujeres (7).

Las manifestaciones clínicas son variables, usualmente inicia con fiebre, tos, debilidad y posterior disnea, anorexia y pérdida de peso. La disnea generalmente es severa, especialmente cuando la enfermedad progresa de manera acelerada. La hemoptisis es infrecuente y rara vez pone en riesgo la vida del paciente. El diagnóstico se obtiene sólo después de varias semanas (aproximadamente 6-13). En algunos de los pacientes se han descrito manifestaciones clínicas y radiológicas del síndrome de dificultad respiratoria aguda (SDRA). Otras manifestaciones poco comunes incluyen dolor torácico, diaforesis nocturna, artralgias y mialgias leves. El neumotórax y/o neumomediastino puede ser otra característica de baja frecuencia. La exploración física es inespecífica, a menudo se auscultan estertores finos en las zonas afectadas, pero no hay sibilancias en contraste con otras neumonías intersticiales $(7,9)$.

Los tres principales patrones radiológicos de la NOC son: 1) Múltiples opacidades alveolares usualmente bilaterales y migratorias (típico de la NOC); 2) Opacidad solitaria que puede ser en forma de nódulo o masa (NOC focal) y 3) Opacidades infiltrantes, las cuales son reticulares y alveolares superpuestas (NOC infiltrante). En un estudio de precisión diagnóstica la serie de pacientes con neumonía intersticial idiopática a quienes se les realizó (TAC) el diagnóstico correcto de la NOC fue el más alto $(79 \%$ de los casos) lo que destaca la importancia de la evaluación radiológica en esta patología $(7,8)$. Los hallazgos de laboratorio son de poco valor. Por lo general leucocitosis, con neutrofilia y leve incremento de la VSG y la PCR. Ocasionalmente los ANAS y el FR están presentes en títulos bajos en ausencia de enfermedades del tejido conectivo. El lavado broncoalveolar demuestra un patrón mixto, moderado aumento de los linfocitos (aproximadamente de 25 a $45 \%$ ) con una disminución del cociente CD4/CD8 en la mayoría de los casos, neutrófilos (10\%) y eosinófilos (en promedio $5 \%$ y siempre menos de $25 \%$, límite inferior aceptado para el diagnóstico de neumonía eosinofílica). La certeza diagnóstica requiere estudio histopatológico; la videotoracoscopia asistida provee adecuadas condiciones de seguridad y permite obtener suficiente tejido pulmonar. La biopsia transbronquial, a pesar de que las muestras son pequeñas, sigue contribuyendo al diagnóstico en la mayoría de los casos, en donde la clínica y radiología dan una alta probabilidad pretest. Múltiples etiologías se han descrito en NOC incluyendo infecciones bacterianas, virus, parásitos y hongos; medicamentos como antibióticos, bleomicina, amiodarona y los FARMEs. También se ha reportado casos posterior a trasplante de órganos, radioterapia de tórax, neoplasias hematológicas y enfermedades del tejido conectivo como miosistis/polimiositis, esclerodermia, síndrome de Sjögren, lupus eritematoso sistémico y artritis reumatoide (9).

Los datos en la literatura de AR y NOC son escasos, en 1991 Rees y colaboradores reportaron tres casos de pacientes con AR, con síntomas respiratorios y patrón restrictivo en la función pulmonar, el diagnóstico se estableció por biopsia y hubo adecuada respuesta al manejo con dosis alta de esteroides (10). Posterior a esto se han reportado casos similares con NOC luego de las manifestaciones clásicas de la AR; sin embargo, muy pocos como este paciente. Ippolito y colaboradores describieron una mujer de 68 años con síntomas pulmonares y opacidades en la radiografía quien después de seis meses presentó poliartritis simétrica; la biopsia pulmonar mostró características compatibles con la denominada actualmente NOC, fue manejado con $60 \mathrm{mg}$ de prednisona al día con adecuada respuesta (11). Araki y colaboradores reportaron el caso de una mujer de 49 años que presentó tos productiva, fiebre y dolor torácico, que fue admitida al hospital de la Universidad de Nagoya. Su radiografía de tórax mostró opacidades en ambos campos pulmonares y derrame pleural izquierdo. El FR fue positivo en el suero y el líquido pleural. Los antibióticos fueron ineficaces. La biopsia transbronquial reveló fibrosis intraalveolar, así como inflamación intersticial. Por sospecha clínica de NOC se realizó biopsia pulmonar abierta que reveló hiperplasia linfoide con formación de centro germinal. El paciente fue diagnosticado con compromiso pulmonar previo a la artritis reumatoide (12). Hace tres años Cavallasca y colaboradores reportaron el caso de un hombre de 65 años quien desarrolló síntomas pulmonares con radiología y biopsia pulmonar abierta que confirmó NOC y que seis meses después desarrolló síntomas articulares con FR y anti-CCP positivos. Hubo respuesta adecuada al esteroide con posterior asociación de metotrexate y luego etanercept (13). 
Hay que destacar la asociación de NOC concomitante al inicio de los síntomas articulares, para lo cual referimos el caso de Katoy colaboradores de una paciente femenina de 64 años quien presentó poliartritis simétrica de manos, rigidez matinal, FR positivo y edema bilateral con fóvea. La resonancia magnética de manos mostró cambios típicos de RS3PE (sinovitis simétrica seronegativa remitente con edema en fóvea). Concomitante al dolor articular refería tos y fiebre, la TAC de tórax mostró imágenes compatibles con NOC. El dolor articular y síntomas respiratorios mejoraron con $30 \mathrm{mg}$ de prednisolona día (14).

En nuestro caso hay que resaltar que el diagnóstico de AR se realizó con anti-CCP y no con FR, como en los reportes mencionados. Recordando que la especificidad de los anticitrulinados es de $95 \%$ comparado con $85 \%$ del FR (15). Por otra parte la respuesta al esteroide fue satisfactoria tanto clínica como radiológicamente. Tradicionalmente la dosis recomendada de corticosteroide sistémico es de 0.75 a $1.5 \mathrm{mg} / \mathrm{kg} /$ día de inicio con reducción de la dosis según respuesta y con uso continuo hasta por un año. No obstante en el contexto de AR es importante la asociación de FARMEs con la salvedad del seguimiento estricto por toxicidad pulmonar por algunos de ellos. En NOC no respondedora y no asociada a AR se han usado medicamentos citotóxicos como la azatriopina y la ciclofosfamida, recordando que la recaída varía entre $13-58 \%$ (9).

\section{Conclusión}

La NOC posterior a las manifestaciones articulares es la forma más común de presentación en la AR, no obstante destacamos el caso de la paciente donde la NOC fue la primera manifestación y donde los anti-CCP fueron parte fundamental en el diagnóstico.
Agradecimiento

Doctor Germán Barbosa Serrano, Patólogo Instituto Nacional de Cancerología

\section{Referencias}

1. Scott DL, Wolfe F, Huizinga TW. Rheumatoid arthritis. Lancet 2010; 376: 1094-108

2. Gabriel SE, Michaud K. Epidemiological studies in incidence, prevalence, mortality, and comorbidity of the rheumatic diseases. Arthritis Res Ther 2009; 11: 229.

3. Antin-Ozerkis D, Evans J, Rubinowitz A, Homer RJ, Matthay RA. Pulmonary manifestations of rheumatoid arthritis. Clin Chest Med. 2010; 31: 451-78.

4. Kinder AJ, Hassell AB, Brand J, Brownfield A, Grove M, Shadforth MF. The treatment of inflammatory arthritis with methotrexate in clinical practice: treatment duration and incidence of adverse drug reactions. Rheumatology 2005; 44: 61-6.

5. Epler GR, Colby TV, McLoud TC, Carrington CB, Gaensler EA. Bronchiolitis obliterans organizing pneumonia. N Engl J Med 1985; 312: 152-8.

6. White ES, Tazelaar HD, Lynch JP. Bronchiolar complications of connective tissue diseases. Semin Respir Crit Care Med 2003; 24: 543-66.

7. Cordier JF. Cryptogenic organizing pneumonia. Clin Chest Med 2004; 25: 727-38.

8. Johkoh T, Müller NL, Cartier Y, Kavanagh PV, Hartman TE, Akira M, et al. Idiopathic interstitial pneumonias: diagnostic accuracy of thin section CT in 129 patients. Radiology 1999; 211: 555-60.

9. Cordier JF. Cryptogenic organising pneumonia. Eur Respir J 2006; 28: 422-46.

10. Rees JH, Woodhead MA, Sheppard MN, du Bois RM. Rheumatoid arthritis and cryptogenic organizing pneumonia. Respir Med 1991; 85: 243-6.

11. Ippolito JA, Palmer L, Spector S, Kane PB, Gorevic PD. Bronchiolitis obliterans organizing pneumonia and rheumatoid arthritis. Semin Arthritis Rheum 1993; 23: $70-8$

12. Araki N, Matsumoto K, Taki F, Suzuki R, Takagi K, Kondoh Y, et al. A case of interstitial pneumonia antedating rheumatoid arthritis--differentiation from idiopathic BOOP. NihonKyobu Shikkan Gakkai Zasshi 1994; 32: 249-5.

13. Cavallasca JA, Caubet M, Helling CA, Tate GA. Cryptogenic organizing pneumonia (COP), as presentation of rheumatoid arthritis. Rheumatol Int 2008; 29: $99-101$.

14. Kato T, Ubara Y, Sawa N, Tagami T, Katori H, Takemoto F , et al. An abrupt onset of seropositive polyarthritis with prominent distal tenosynovitis concomitan with bronchiolitis obliteransorganizing pneumonia (BOOP): consideration of the relationship with RS3PE syndrome. Intern Med 2004; 43: 143-7.

15. Nishimura K, Sugiyama D, Kogata Y, Tsuji G, Nakazawa T, Kawano S, et al. Meta-analysis: Diagnostic Accuracy of Anti-Cyclic Citrullinated Peptide Antibody and Rheumatoid Factor for Rheumatoid Arthritis. Ann Intern Med 2007; 146: 797-808. 